\title{
ResearchOnline@JCU
}

This is the Accepted Version of a paper published in the journal Animal Behaviour

Rymer, Tasmin, Schradin, Carsten, and Pillay, Neville (2008) Social transmission of information about novel food in two populations of the African striped mouse, Rhabdomys pumilio. Animal Behaviour, 76 (4). pp. 1297-1304.

http://dx.doi.org/ 10.1016/j.anbehav.2008.06.014 


\section{Social transmission of information about novel food in two populations of the African striped mouse Rhabdomys pumilio}

TASMIN RYMER*, CARSTEN SCHRADIN $\dagger *$, NEVILLE PILLAY*

*School of Animal, Plant and Environmental Sciences, University of the Witwatersrand, South Africa

$†$ Behavioural Biology, Zoological Institute, University of Zurich

Correspondence: T. Rymer. School of Animal, Plant and Environmental Sciences, University of the Witwatersrand, Private Bag 3, Wits 2050, South Africa (tasmin@gecko.wits.ac.za) C. Schradin is based at the Zoological Institute, University of Zurich, Winterthurerstrasse 190, 8057 Zurich, Switzerland

N. Pillay is based at the University of the Witwatersrand (same address as corresponding author)

* This is the Accepted Version of a paper published in the journal Animal Behaviour: Rymer, T., Schradin, C. \& Pillay, N. 2008. Social transmission of information about novel food in two populations of the African striped mouse, Rhabdomys pumilio. Animal Behaviour, 76, 1297-1304.

Note: Corresponding author's email has changed: Tasmin.Rymer@jcu.edu.au. 
Social learning involves the transmission of information from demonstrators to conspecifics. The mother is expected to be the main demonstrator in solitary species, whereas several individuals can be demonstrators in group-living species. We studied social learning about novel food in two populations of the African striped mouse, with different social systems: a desert population (group living with paternal care and natal philopatry) and a grassland population (solitary, paternal care in captivity only and natal dispersal). We predicted that both parents would be reliable demonstrators for desert striped mice but only the mother would be a demonstrator for grassland striped mice. Adults and unweaned young were assigned to one of five treatments in captivity: (1) father or (2) mother fed novel food away from young; (3) novel food fed to both adults with young present; and (4) father or (5) mother fed mouse cubes (control) away from young. Juveniles from all treatments individually received novel food after weaning. The responses of juveniles to novel food were greater (shorter latency, more sniffs) when the mother was the demonstrator, regardless of population. Mothers may be more reliable demonstrators than fathers because information can be transmitted using multiple channels (olfaction, lactation). Our study also showed that fathers were more reliable demonstrators and responses to the novel food were greater in desert than grassland striped mice. These population differences reflect the different social organization of the populations and the unpredictable availability of highly nutritious food in the desert.

Keywords: African striped mouse; demonstrator reliability; food novelty; information transfer; paternal care; Rhabdomys pumilio; social learning

\footnotetext{
* This is the Accepted Version of a paper published in the journal Animal Behaviour: Rymer, T., Schradin, C. \& Pillay, N. 2008. Social transmission of information about novel food in two populations of the African striped mouse, Rhabdomys pumilio. Animal Behaviour, 76, 1297-1304.

Note: Corresponding author's email has changed: Tasmin.Rymer@jcu.edu.au.
} 
Learning is a cognitive process (Duncan \& Petherick 1991) enabling animals to acquire information about the state of their immediate environment (Katz \& Lachlan 2003) and their own individual state (Duncan \& Petherick 1991). An inherent part of learning concerns information about food, in particular determining whether food is palatable and nontoxic, and thus safe to consume (Galef \& Clark 1971), and the location of this food in time and space (Ostfeld 1985).

An individual may learn about novel foods individually through, for example, 'trial and error' learning (Noble \& Franks 2002), but such learning creates the risk of ingesting noxious or unpalatable food. Alternatively, group living may promote social learning, which involves learning about the environment through the observation of (Heyes 1993) and interaction with (Katz \& Lachlan 2003) conspecifics, or the products of their behaviours (Heyes 1994). This may reduce the costs often associated with individual learning (Zentall 2006). Individuals may be drawn to an area by the activity and behaviour of others (i.e. local enhancement; Range \& Huber 2007), which promotes opportunities for learning through imitation or observational learning. Imitation is a process that involves learning about (Heyes 1993) and accurately replicating (Zentall 2006) a new behaviour, or part thereof (Whiten et al. 2004), through the direct observation of conspecifics. Observational learning also involves learning about new behaviours by observing conspecifics, but does not lead to a duplication of the behaviour (Hall 1963).

Demonstrators are individuals that facilitate the learning process in conspecifics (Sherwin et al. 2002). Solitary and social mammals differ in their access to the number and type of demonstrators available to them. Solitary mammals principally rely on their mothers during the preweaning phase of their lives. For example, juvenile eastern woodrats, Neotoma floridana, showed a flavour preference for food to which they were exposed when suckling (Post et al. 1998). Social species, such as dwarf hamsters, Phodopus campbelli (Lupfer et al. 
2003) and chimpanzees, Pan troglodytes schweinfurthii (Lonsdorf 2006), may also rely principally on their mothers to facilitate learning. Moreover, in social species, young may have the opportunity to learn from other adults or from siblings, if they associate with them during the preweaning phase. In addition, learning in a social context can occur throughout an individual's life span in group-living species, since there may be many opportunities for the exchange of information between individuals (Visalberghi \& Addessi 2001), including learning about novel food (Nicol 1995). Observing conspecifics feeding can reduce fear of these novel foods (neophobia) and increases the likelihood of their acceptance (Galloway et al. 2005).

The African striped mouse is a small $( \pm 40 \mathrm{~g})$ diurnal murid rodent with a widespread distribution in southern Africa. It offers a unique opportunity to investigate the influence of demonstrators on the ability of offspring to learn about novel foods, as this species shows regional differences in sociality. In the arid succulent karoo of South Africa, striped mice live in groups of three or four females and one male (Schradin \& Pillay 2004). In the moist eastern grassland regions, this species is solitary and males do not associate with females or pups after parturition (Schradin \& Pillay 2005a). In the natural environment, offspring of desert striped mice typically remain philopatric for a number of months, whereas grassland offspring stay with the mother for only a few weeks before dispersing soon after weaning (Schradin \& Pillay 2005a). Differences in social organization and mating strategy between desert and grassland striped mice may be responses to a particular set of environmental conditions (Schradin 2005; Schradin \& Pillay 2005b). In the desert, female striped mice form small groups together with their overwintering philopatric young because of a limited availability of suitable nesting sites, high population density and the need for huddling in groups; a male associates with a group and has access to mates. Conversely, in grasslands, females have large intrasexually nonoverlapping territories because food is patchily 
distributed. Young disperse after weaning since nesting sites are not limited and there is little need for huddling in the dense vegetation. Males adopt a roaming mating strategy by visiting several receptive females.

In captivity, males of both populations show extensive amounts of direct paternal care, with all the behaviours shown by females (e.g. huddling and retrieving) apart from lactation (Schradin \& Pillay 2003). Paternal care has been demonstrated through direct observations and experimental manipulations only in free-living desert striped mice (Schradin \& Pillay 2003). Since males do not associate with females and pups in the grassland populations, the opportunities for paternal care may not exist, suggesting that the behaviour is plesiomorphic in grass- land populations.

Apart from providing direct care, paternal behaviour may provide an opportunity for offspring to learn about novel foods from the father. Blissett et al. (2006) indicated that human fathers are more likely to control the feeding practices of their sons. We are not aware of any studies that have investigated the role of the father in the development of socially acquired food choice in a mammal, and only one study has investigated the role of the father as a demonstrator (Hatch \& Lefebvre 1997).

Using an experimental protocol in which either one or both parents were demonstrators, we compared the responses of juvenile desert and grassland striped mice to a novel food to investigate evidence of social learning via olfactory, gustatory and visual cues. We predicted population differences in social learning, since desert striped mice (in the natural environment) have access to a greater number of demonstrators for a longer period of time than grassland striped mice (Schradin \& Pillay 2005a). Specifically, we predicted that, because of population-specific differences in the occurrence of paternal care in nature and presumably selection for fathers to be demonstrators in desert striped mice, both parents would be reliable demonstrators for young striped mice from this population, but only 
mothers would be demonstrators for grassland young. This prediction assumes that offspring are genetically predisposed to learn from their fathers in the desert but not the grassland striped mice. However, we were mindful that males from both populations show paternal care in captivity, so we asked whether learning from the fathers may occur in both populations because of the postpartum association between fathers and offspring in the laboratory. If so, learning in both populations could be the result of social/environmental influences. We also predicted that desert striped mice would respond faster to novel food than grassland striped mice, because of the unpredictability of food availability in the desert and the low likelihood of encountering food of high nutritional value (Schradin 2007).

\section{METHODS}

Striped mice used in this study were F1-F4 generation individuals derived from Goegap Nature Reserve, Northern Cape Province, South Africa (29.40 S, 17.53 E, designated desert striped mice) and Cullinan, Gauteng Province, South Africa (25.40 S, 28.31 E, designated grassland striped mice). They were housed in the Milner Park Animal Unit at the University of the Witwatersrand, under partially controlled environmental conditions (14:10 h light: dark regime, lights on at 0500 hours; $20-24{ }^{\circ} \mathrm{C} ; 30-60 \%$ relative humidity).

Twenty breeding pairs, 10 from each population, were established. Breeding pairs were housed in glass tanks (46 x $30 \mathrm{~cm}$ and $32 \mathrm{~cm}$ high). The floor of the cages was covered with a layer of wood shavings for bedding. A plastic nestbox (27 x $20 \mathrm{~cm}$ and $17 \mathrm{~cm} \mathrm{high)} \mathrm{was}$ provided. Nesting material comprised a handful of dry grass weekly and approximately $5 \mathrm{~g}$ of paper towel twice weekly. One cardboard toilet roll/paper cup and twigs were provided weekly for behavioural enrichment. Subjects had access to water and Epol (Epol, Pretoria 
West, South Africa) mouse cubes ad libitum. The diet was supplemented with fresh fruit or vegetables daily and approximately $5 \mathrm{~g}$ of seed at least twice a week.

Our intention in this study was to obtain five consecutive litters per breeding pair, and randomly assign each litter to one of five different treatments (see below). Fifteen pairs produced the required five litters, whereas three grassland and two desert pairs each produced three litters only. We used data from an additional five pairs (two litters per pair) to achieve the required sample size.

Experiments involved exposing demonstrators (parents) to novel or standard laboratory food (mouse) cubes on one occasion per litter when pups were either 10 or 12 days old (i.e. when striped mice start eating solid food; Pillay 2000). Litters were separated from their parents at 21 days of age, a few days before the birth of the next litter (interlitter interval 2325 days). The five treatments were as follows. (1) Father removed + novel food (FRN): the father was removed from the breeding tank and housed in a holding cage $(36 \times 16 \mathrm{~cm}$ and 20 $\mathrm{cm}$ high) in a different room for $5 \mathrm{~min}$. During this time, he had access to approximately $30 \mathrm{~g}$ of boiled egg as a novel food. After $5 \mathrm{~min}$ he was returned to the home tank. Chopped boiled egg was used as the novel food because the striped mice used in this study had never been exposed to egg previously, it has high nutritional value, and striped mice have a high preference for egg in the laboratory (N. Pillay, personal observation). (2) Mother removed + novel food (MRN): as in FRN, but the mother was removed. (3) Mother and father in home tank + novel food (MFN): approximately $30 \mathrm{~g}$ of boiled egg was fed to the breeding pair while their unweaned offspring were present in the breeding tank. (4) Father removed + standard food (FRS): the father was removed from the breeding tank, fed approximately $30 \mathrm{~g}$ of mouse cubes in a holding cage for $5 \mathrm{~min}$, and then returned to the home tank. (5) Mother removed + standard food (MRS): as in FRS, but the mother was removed. We used 40 juveniles (20 desert and 20 grassland) for each treatment. The FRS and MRS treatments 
served as controls. Apart from food, holding cages used in the FRN, MRN, FRS and MRS treatments contained wood shavings, and the animals had access to water and shelter. All demonstrators consumed the egg or mouse cubes. The amount of egg consumed ranged from $10 \mathrm{~g}$ (FRN, MRN) to $22 \mathrm{~g}(\mathrm{MFN})$.

Juveniles were housed individually in holding cages under the conditions described above once they were weaned from their parents at 21 days of age. Two juveniles, one of each sex from each litter, were chosen randomly and housed individually overnight in rectangular, holding cages ( $45 \times 30 \mathrm{~cm}$ and $30 \mathrm{~cm}$ high). Juveniles were tested individually since striped mice forage alone in nature (Schradin \& Pillay 2004). The floor was covered with wood shavings and a handful of dry grass, $5 \mathrm{~g}$ of paper towel and a cardboard toilet roll were provided for cover. Water, approximately $30 \mathrm{~g}$ of mouse cubes and a small piece of apple were provided. Tests were conducted between 0730 and 1100 hours on the following day. All cover, excess wood shavings and all mouse cubes were removed from the holding cages to facilitate video recording and scoring of the behavioural responses of test subjects; in pilot studies, cage furnishings and the mouse cubes obscured our view of test subjects. Approximately $30 \mathrm{~g}$ of chopped boiled egg was placed into a petri dish, approximately $4 \mathrm{~cm}$ from the front of the holding cage and approximately $6 \mathrm{~cm}$ from the side. The position of the petri dish containing the boiled egg was alternated along the long axis of the cage between treatments to account for positional biases. The behaviour of test subjects was video recorded for $30 \mathrm{~min}$ following the introduction of the egg. No observers were present in the room during taping sessions. Using continuous sampling, we scored the behaviour of test subjects for the 30 min taping session, and recorded the latency to make first contact with the egg, the number of sniffs of the egg in the first 5 min after making contact and the latency to start consuming the egg. 


\section{Ethical Note}

We provided animals with environmental enrichment (as described above). The experimental procedures used here had no obvious negative effects on the welfare of the striped mice. After tests, juveniles were returned to the captive striped mouse colony and used in other breeding experiments when they were fully grown. This study was approved by the Animal Ethics Screening Committee of the University of Witwatersrand.

\section{Statistical Analysis}

For all analyses we used Statistica 7.1 (Statsoft Inc, www.statsoft.com). The data set met the assumptions of normality (Shapiro-Wilk's test) and homogeneity of variances (Levene's test) after the behavioural variables were square-root (number of sniffs) or log (latency to approach and consume) transformed. Each dependent variable was analysed with mixed models, using the general linear model (GLM) module. In all analyses, population, sex of test subjects, treatment and litter order (i.e. the first to fifth litter produced by a pair, to account for their previous breeding experience) were entered as fixed categorical predictors. Random effects included breeding pair identity as well as litter identity nested in treatment and in breeding pair identity, so as to account for the similar genetic and/or environmental histories of test subjects (i.e. different litters per breeding pair were used in different treatments and two littermates, one male and one female, were used in each treatment). In addition, not all pairs produced five litters and we used two litters each from some other breeding pairs to achieve the required sample size. Litter size was included as a continuous predictor (covariate) in the analyses. Tukey honest significant difference (HSD) post hoc tests were used to identify specific differences. The model-level significance was determined at $\alpha=$ 0.05. However, because the measurements for the three dependent variables are interrelated, 
we adjusted alpha levels using a Bonferroni sequential adjustment $\left(\alpha^{\prime}=0.017\right)$ prior to conducting post hoc tests. All tests were two tailed.

\section{RESULTS}

\section{Latency to Make First Contact}

Offspring of desert striped mice made first contact with the novel food (boiled egg) significantly faster than their grassland counterparts (Table 1, Fig. 1). There was a significant treatment effect, with offspring from both populations making first contact with the novel food significantly faster in the MRN and MFN treatments (mother was the demonstrator or offspring had direct exposure to egg before weaning), followed by offspring in the MRS (mother fed standard food) and FRN (father fed novel food). The latency to make first contact was significantly longest in the FRS treatment (father fed mouse cubes; Table 1, Fig. 1). There was a significant population*treatment interaction, which showed that offspring from the desert population responded faster to the novel food in the MRN, MFN, FRN treatments (i.e. direct or indirect prior exposure to egg) than those from the grassland population, and apart from the FRS treatment, desert striped mice responded faster than grassland striped mice for all other treatments. In addition, the slowest responses were recorded in grassland individuals in the FRN and FRS treatments (i.e. when the fathers were demonstrators of novel and standard food; Table 1, Fig. 1).

The following variables were not significant predictors of the latency to make first contact with novel food: sex; litter order; population*sex; population*litter order; sex*treatment; sex*litter order; treatment*litter order; breeding pair identity; litter identity (nested in treatment and in breeding pair identity); and litter size (Table 1). 


\section{Number of Sniffs}

Offspring of the desert striped mice sniffed the egg significantly more often than offspring of grassland striped mice (Table 1, Fig. 2). In addition, offspring from both populations sniffed the egg significantly more often in the MRN (mother fed egg) treatment than the MFN and FRN treatments, and least often in the MRS and FRS treatments (mother and father fed mouse cubes; Table 1, Fig. 2).

Sex, litter order, population*sex, population*treatment, population*litter order, sex*treatment, sex*litter order, treatment*litter order, breeding pair identity, litter identity (nested in treatment and in breeding pair identity) and litter size did not influence the number of sniffs of the novel food (Table 1).

\section{Latency to Consume}

The latency to start consuming the egg was shorter for offspring of desert striped mice than those of grassland striped mice (Table 1, Fig. 3). However, offspring from both populations took significantly less time to start consuming food in the MRN and MFN (mother and offspring exposed to novel food) treatments than the MRS treatment, and took longest to start consuming food in the FRN and FRS treatments (i.e. when the father was fed away from offspring; post hoc tests; Fig. 3). There was a significant population*treatment interaction, which showed that desert striped mice in the MFN, MRN and MRS treatments responded the quickest, and grassland striped mice responded the slowest (Table 1, Fig. 3). Offspring from the desert population did not take less time to start consuming novel food than those from the grassland in the FRN treatment (i.e. father fed novel food; Fig. 3). All test subjects consumed the egg during experiments.

The latency to start consuming food was not influenced by the sex, litter order, population*sex, population*litter order, sex*treatment, sex*litter order, treatment*litter order, 
breeding pair identity, litter identity (nested in treatment and in breeding pair identity) and litter size (Table 1).

\section{DISCUSSION}

Our results indicate that social learning influences the responses of young striped mice to novel food in both desert and grassland populations. Even though the response of young striped mice to novel food was not an 'all or nothing' reaction, since they reacted to novel food even when they did not have prior experience with it (FRS and MRS treatments), their

responses were greater (faster or more numerous) in the treatments in which they had direct (MFN) or indirect (FRN, MRN) prior exposure to the novel food.

Treatment was also an important predictor of social learning, since young striped mice showed shorter latencies to make first contact and to start consuming novel food and more investigatory behaviour when mothers were demonstrators, regardless of population. This indicates that offspring rely mainly on their mothers for learning about novel food. The importance of the mother for information transfer to offspring regarding novel food has been shown in a number of species, such as house mice, Mus domesticus (Valsecchi et al. 1989) and domestic chickens, Gallus gallus (Nicol 2006).

Mammals use olfactory cues to assimilate information from social interactions (Laland \& Plotkin 1991; Galef \& Allen 1995). In particular, offspring may be exposed to olfactory cues from food on the breath of conspecifics returning from foraging bouts, as occurs in dogs, Canis familiaris (Lupfer-Johnson \& Ross 2007). Olfactory cues are important for social interactions in striped mice (Pillay et al. 2006), and our study shows that olfaction is also important for acquiring information about novel food from conspecifics (i.e. MRN, FRN, MFN treatments). Nonetheless, other cues, such as auditory signals (e.g. Elowson et al. 
1991), visual cues (e.g. Valsecchi et al. 1989) and molecular (taste) cues transmitted in the mother's milk (e.g. Wells \& Hepper 2006), when used in conjunction with olfactory cues, may provide a stronger channel for the transfer of information (Taylor et al. 2007). Other studies have also shown that prenatal exposure to chemical stimuli in the mother's diet can influence postnatal food preferences (e.g. dogs, Wells \& Hepper 2006).

Therefore, we suggest that striped mice mothers may be more reliable demonstrators of novel food than fathers because of the multiple channels of information transfer. Offspring responded just as fast to novel food when it was placed directly into their home cage (MFN treatment) as when the mother was the demonstrator (MRN), further supporting the hypothesis that multiple cues may be required for learning about novel food. The parents used in the present study were exposed to novel food when their offspring were 10-12 days old, the transition age between suckling and eating solid food in striped mice (Pillay 2000). This suggests that at least two channels for the transfer of information would have been present for the young: through olfactory cues and gustatory cues in the mother's milk.

The ability to learn from another individual is context dependent, and influenced by both the demonstrator and the observer (Nicol 2006). Hence, young may not learn about novel food from the father if they spend more time with the mother. This is not the case for striped mice, however, since fathers spend similar amounts of time with young as mothers do, at least in captivity (Schradin \& Pillay 2003). Instead, we propose that male striped mice are not as reliable as mothers as demonstrators of novel food because there are fewer channels for information transfer from fathers. Because our study relied primarily on the olfactory transmission of information from fathers, it is possible that olfactory cues, in isolation from other cues, from the father may not be sufficient for the reliable transmission of information to the offspring. In white-footed mice, Peromyscus leucopus, weaned offspring follow their fathers, but not mothers, on foraging bouts (Schug et al. 1992). In addition, Galef \& Clark 
(1971) stated that visual cues may be important in guiding young to a food source. It is thus possible that young striped mice may also require visual cues from their fathers, in addition to olfactory cues, to ensure reliability of information transfer. Desert striped mice forage alone, but because groups occupy small territories, group members feed in close proximity (Schradin \& Pillay 2004, 2005a), potentially facilitating learning from visual cues.

In treatments where fathers were demonstrators (FRN, FRS), desert striped mice responded quicker to the novel food than their grassland counterparts. In nature, population differences in paternal care are expected in striped mice because males associate with females and their pups in the desert but not in the grassland (Schradin \& Pillay 2005b). Although grassland striped mice show paternal care in the laboratory (Schradin \& Pillay 2003), offspring may still be constrained from learning from their fathers, even though the opportunities for social learning in the experimental set-up in the laboratory were the same for both populations. In wild grassland striped mice, offspring presumably rely on their mothers as the only reliable source of information transfer, and there is no selection pressure to learn from the father as he does not associate with the mother after conception (Schradin \& Pillay 2005a). Our results therefore support the prediction that learning from the father has a genetic basis that is present in desert but not grassland striped mice.

Although female striped mice are more reliable demonstrators of novel food, fathers still provide vital care for juveniles in the desert population. Fathers lick and huddle with pups to the same extent as mothers, and will retrieve displaced pups back into the nest (Schradin \& Pillay 2004). Night-time temperatures in winter in the succulent karoo (from where our desert population originated) often fall below $0{ }^{\circ} \mathrm{C}$ and the presence of the father in the nest during these times is important for offspring growth (Schradin \& Pillay 2005c). Indeed, Schradin \& Pillay (2003) showed that pup development is better under biparental care than exclusive maternal care, indicating that paternal care may have important fitness-enhancing benefits. 
In all treatments, desert striped mice responded faster and with more intensity to novel food than their grassland counterparts. This could be a result of ecological constraints imposed by the desert environment or of genetically determined personality differences of striped mice from these two populations (A. Hinze \& N. Pillay, unpublished data). We observed that, compared to grassland striped mice, desert striped mice are bolder in captivity, spending more time outside their nestboxes and more time investigating novel objects placed in their cages. However, as striped mice from both populations still responded to novel food, we postulate that the faster responses by desert striped mice may be an adaptation for exploiting unpredictable palatable food in the variable desert environment (Schradin 2007), even though such areas do have a stable year-round food supply (Schradin \& Pillay 2004). Perrin (1980) described the striped mouse as an opportunistic omnivore, taking advantage of transient but nutritious food resources. Goegap Nature Reserve (from where the desert striped mice originated) experiences erratic winter rainfall, with an average of $160 \mathrm{~mm}$ of rain per year (Schradin 2005) and thus there is marked seasonal variation in food abundance.

Therefore, the probability of encountering a palatable, highly nutritious food decreases during the dry season (Schradin 2007). As a consequence, striped mice from the desert show high levels of exploration (A. Hinze \& N. Pillay, unpublished data), which improves their encounter rate with food.

In conclusion, social learning occurs in both desert and grassland striped mice and mothers are more reliable demonstrators than fathers for offspring learning about novel food. This may be because offspring are dependent on their mothers for at least the first 10 days of their lives (Pillay 2000), when they can acquire information about palatable food from their mothers via multiple channels, such as olfactory cues and molecular cues transmitted in the milk. Two other important findings in our study were that (1) fathers of desert striped mice were more reliable demonstrators of novel food than fathers of grassland striped mice, despite 
both being present and showing paternal care in captivity, and (2) desert striped mice responded faster to novel food than their grassland counterparts, even though individuals of both populations were adequately provisioned in captivity. These population differences in social learning and responses to novel food may be related to differences in the social organization of desert (social) and grassland (solitary) striped mice and the unpredictability of

highly nutritious food in the desert. Ultimately, population-specific behavioural responses of striped mice may be genetically determined adaptations for life in the harsh desert or more stable grassland habitats.

\section{Acknowledgements}

We are grateful to Jennifer Barnetson who assisted with data collection. Funding was provided by the National Research Foundation (grant number: 2069110) and the University of the Witwatersrand (Anderson Capelli Fund). We thank the editor and two anonymous referees for their useful suggestions which helped improve the manuscript.

\section{References}

Blissett, J., Meyer, C. \& Haycraft, E. 2006. Maternal and paternal controlling feeding practices with male and female children. Appetite, 47, 212-219.

Duncan, I. J. H. \& Petherick, J. C. 1991. The implications of cognitive processes for animal welfare. Journal of Animal Science, 69, 5017-5022.

Elowson, A. M., Tannenbaum, P. L. \& Snowdon, C. T. 1991. Food-associated calls correlate with food preferences in cotton-top tamarins. Animal Behaviour, 42, 931-937.

Galef, B. G., Jr \& Allen, C. 1995. A new model system for studying behavioural traditions in animals. Animal Behaviour, 50, 705-717. 
Galef, B. G., Jr \& Clark, M. M. 1971. Social factors in the poison avoidance and feeding behaviour of wild and domesticated rat pups. Journal of Comparative Physiology and Psychology, 75, 341-357.

Galloway, A. T., Addessi, E., Fragaszy, D. M. \& Visalberghi, E. 2005. Social facilitation of eating familiar food in Tufted Capuchins (Cebus paella): Does it involve behavioural coordination? International Journal of Primatology, 26, 181-188.

Hall, K. R. L. 1963. Observational learning in monkeys and apes. British Journal of Psychology, 54, 201-226.

Hatch, K. K. \& Lefebvre, L. 1997. Does father know best? Social learning from kin and non-kin in juvenile ringdoves. Behavioural Processes, 41, 1-10.

Heyes, C. M. 1993. Imitation, culture and cognition. Animal Behaviour, 46, 999-1010.

Heyes, C. M. 1994. Social learning in animals: categories and mechanisms. Biological Reviews, 69: 207-231.

Katz, M. \& Lachlan, R. F. 2003. Social learning of food types in zebra finches (Taenopygia guttata) is directed by demonstrator sex and feeding activity. Animal Cognition, 6, 11-16.

Laland, K. N. \& Plotkin, H. C. 1991. Excretory deposits surrounding food sites facilitates social learning of food preferences in Norway rats. Animal Behaviour, 41, 997-1005.

Lonsdorf, E. V. 2006. What is the role of mothers in the acquisition of termite-fishing behaviours in wild chimpanzees (Pan troglodytes schweinfurthii)? Animal Cognition, 9, 36-46.

Lupfer, G., Frieman, J. \& Coonfield, D. 2003. Social transmission of flavour preferences in two species of hamsters (Mesocricetus auratus and Phodopus campbelli). Journal of Comparative Psychology, 117, 449-455.

Lupfer-Johnson, G. \& Ross, J. 2007. Dogs acquire food preferences from interacting with recently fed conspecifics. Behavioural Processes, 74, 104-106. 
Nicol, C. J. 1995. The social transmission of information and behaviour. Applied Animal Behaviour Science, 44, 79-98.

Nicol, C. J. 2006. How animals learn from each other. Applied Animal Behaviour Science, 100, 58-63.

Noble, J. \& Franks, D. W. 2002. Social learning mechanisms compared in a simple environment. In: Artificial Life. Vol. VIII (Ed. by R.K. Standish, M.A.Bedau \& H.A. Abbass), pp. 379-385. Massachusetts: MIT Press.

Ostfeld, R. S. 1985. Limiting resources and territoriality in microtine rodents. American Naturalist, 126, 1-15.

Perrin, M. R. 1980. The feeding habits of two co-existing rodents Rhabdomys pumilio (Sarrman, 1784) and Otomys irroratus (Brants, 1827), in relation to rainfall and reproduction. Acta Oecologica, 1, 71-89.

Pillay, N. 2000. Fostering in the African striped mouse: implications for kin recognition and dominance. Acta Theriologica, 45, 193-200.

Pillay, N., Eborall, J. \& Ganem, G. 2006. Divergence of mate recognition in the African striped mouse (Rhabdomys). Behavioral Ecology, 17, 757-764.

Post, D. M., McDonald, M. W. \& Reichman, O. J. 1998. Influence of maternal diet and perishability on caching and consumption behavior of juvenile eastern woodrats. Journal of Mammalogy, 79, 156-162.

Range, F. \& Huber, L. 2007. Attention in common marmosets: implications for sociallearning experiments. Animal Behaviour, 73, 1033-1041.

Schradin, C. 2005. When to live alone and when to live in groups: ecological determinants of sociality in the African striped mouse (Rhabdomys pumilio, Sparrman, 1784). The Belgian Journal of Zoology (supplement), 135, 77-82. 
Schradin, C. 2007. Information transfer about food locations is not a benefit of group-living in the solitary foraging striped mouse (Rhabdomys pumilio). Journal of Ethology, 25, 8386.

Schradin, C. \& Pillay, N. 2003, Paternal care in the social and diurnal striped mouse (Rhabdomys pumilio): Laboratory and field evidence. Journal of Comparative Psychology, 117, 317-324.

Schradin, C. \& Pillay, N. 2004. The striped mouse (Rhabdomys pumilio) from the succulent karoo, South Africa: A territorial group-living solitary forager with communal breeding and helpers at the nest. Journal of Comparative Psychology, 118, 37-47.

Schradin, C. \& Pillay, N. 2005a. Demography of the striped mouse (Rhabdomys pumilio) in the succulent karoo. Mammalian Biology, 70, 84-92.

Schradin, C. \& Pillay, N. 2005b. Intraspecific variation in the spatial and social organization of the African striped mouse. Journal of Mammalogy, 86, 99-107.

Schradin, C. \& Pillay, N. 2005c. The influence of the father on offspring development in the striped mouse. Behavioral Ecology, 16, 450-455.

Schug, M. D., Vessey, S. H. \& Underwood, E. M. 1992. Paternal behavior in a natural population of white-footed mice (Peromyscus leucopus). American Midland Naturalist, 127, 373-380.

Sherwin, C. M., Heyes, C. M. \& Nicol, C. J. 2002. Social learning influences the preferences of domestic hens for novel food. Animal Behaviour, 63, 933-942.

Taylor, R. C., Buchanan, B. W. \& Doherty, J. L. 2007. Sexual selection in the squirrel treefrog Hyla squirella: the role of multimodal cue assessment in female choice. Animal Behaviour, 74, 1753-1763.

Valsecchi, P., Mainardi, M., Sgoifo, A. \& Taticchi, A. 1989. Maternal influences on food preferences in weanling mice Mus domesticus. Behavioural Processes, 19, 155-166. 
Visalberghi, E. \& Addessi, E. 2001. Acceptance of novel foods in capuchin monkeys: do specific social facilitation and visual stimulus enhancement play a role? Animal Behaviour, 62, 567-576.

Wells, D. L. \& Hepper, P. G. 2006. Prenatal olfactory learning in the domestic dog. Animal Behaviour, 72, 681-686.

Whiten, A. Horner, V., Litchfield, C. A. \& Marshall-Pescini, S. 2004. How do apes ape? Learning \& Behavior, 32, 36-52.

Zentall, T. R. 2006. Imitation: definitions, evidence, and mechanisms. Animal Cognition, 9, $335-353$. 
Table 1. Results of GLM analyses and Tukey HSD post hoc comparisons for the latency to make first contact, the number of sniffs and latency to start consuming novel food.

\begin{tabular}{|c|c|c|c|}
\hline Variables & Latency to approach & Number of sniffs & Latency to consume \\
\hline Population & $F_{1,12.05}=97.72, P<0.001$ & $F_{1,15.30}=24.76, P<0.001$ & $F_{1,18.18}=13.94, P=0.002$ \\
\hline Sex & $F_{1,89.00}=0.13, P=0.721$ & $F_{1,89.00}=0.26, P=0.608$ & $F_{1,89.00}=0.05, P=0.816$ \\
\hline Treatment & $F_{4,44.63}=30.33, P<0.001$ & $F_{4,46.92}=28.89, P<0.001$ & $F_{4,43.14}=31.33, P<0.001$ \\
\hline Litter order & $F_{4,48.23}=1.57, P=0.198$ & $F_{4,50.77}=0.21, P=0.931$ & $F_{4,44.95}=1.52, P=0.213$ \\
\hline Population*Sex & $F_{1,89.09}=0.28, P=0.597$ & $F_{1,89.12}=0.05, P=0.833$ & $F_{1,89.13}=1.46, P=0.231$ \\
\hline Population*Treatment & $F_{4,44.89}=5.08, P=0.002$ & $F_{4,46.94}=2.06, P=0.101$ & $F_{4,43.16}=9.24, P<0.001$ \\
\hline Population*litter order & $F_{4,47.99}=2.38, P=0.065$ & $F_{4,50.89}=0.64, P=0.636$ & $F_{4,44.75}=0.56, P=0.694$ \\
\hline Sex*Treatment & $F_{4,89.09}=0.62, P=0.650$ & $F_{4,89.12}=0.05, P=0.995$ & $F_{4,89.13}=0.94, P=0.445$ \\
\hline Sex*litter order & $F_{4,90.05}=0.53, P=0.718$ & $F_{4,90.60}=0.97, P=0.426$ & $F_{4,90.17}=0.24, P=0.917$ \\
\hline Treatment*litter order & $F_{16,60.57}=1.43, P=0.160$ & $F_{16,52.70}=0.86, P=0.617$ & $F_{16,60.31}=1.24, P=0.267$ \\
\hline Pair identity & $F_{22,41.79}=1.33, P=0.208$ & $F_{22,42.29}=1.13, P=0.353$ & $F_{22,42.51}=0.39, P=0.990$ \\
\hline Litter identity(Treatment) & $F_{44,89.00}=0.78, P=0.823$ & $F_{44,89.00}=0.83, P=0.745$ & $F_{44,89.00}=0.90, P=0.645$ \\
\hline Litter identity(Pair identity) & $F_{44,89.00}=0.54, P=0.986$ & $F_{44,89.00}=0.70, P=0.902$ & $F_{44,89.00}=0.81, P=0.778$ \\
\hline Litter size & $F_{1,42.95}=3.17, P=0.082$ & $F_{1,42.33}=2.13, P=0.152$ & $F_{1,42.56}=1.79, P=0.188$ \\
\hline \multicolumn{4}{|l|}{ Post hoc comparisons ${ }^{1}$} \\
\hline Population & Desert $<$ Grassland & Desert $>$ Grassland & Desert $<$ Grassland \\
\hline \multirow[t]{2}{*}{ Treatment } & $(\mathrm{MRN}, \mathrm{MFN})<(\mathrm{MRS}$, & MRN $>($ MFN, FRN $)>$ & $(\mathrm{MRN}, \mathrm{MFN})<\mathrm{MRS}<$ \\
\hline & FRN) $<$ FRS & (MRS, FRS) & (FRN, FRS) \\
\hline \multirow[t]{5}{*}{ Population $\mathrm{x}$ Treatment $^{2}$} & $\left(\mathrm{MRN}_{\mathrm{D}}, \mathrm{MFN}_{\mathrm{D}}, \mathrm{FRN}_{\mathrm{D}}\right)$ & & $\left(\mathrm{MFN}_{\mathrm{D}}, \mathrm{MRN}_{\mathrm{D}}\right), \mathrm{MRS}_{\mathrm{D}}$ \\
\hline & $\left(\mathrm{MRS}_{\mathrm{D}}, \mathrm{MRN}_{\mathrm{G}}, \mathrm{FRS}_{\mathrm{D}}\right.$ & & $\left(\mathrm{MFN}_{\mathrm{G}}, \mathrm{MRN}_{\mathrm{G}}\right)$ \\
\hline & $\left.\mathrm{MFN}_{\mathrm{G}}\right)$ & & $\left(\mathrm{FRS}_{\mathrm{D}}, \mathrm{MRS}_{\mathrm{G}}, \mathrm{FRN}_{\mathrm{D}}\right.$ \\
\hline & $\left(\mathrm{FRS}_{\mathrm{D}}, \mathrm{MFN}_{\mathrm{G}} \mathrm{MRS}_{\mathrm{G}}\right)$ & & $\left.\mathrm{FRN}_{\mathrm{G}}\right), \mathrm{FRS}_{\mathrm{G}}$ \\
\hline & $\left(\mathrm{FRN}_{\mathrm{G}}, \mathrm{FRS}_{\mathrm{G}}\right)$ & & \\
\hline
\end{tabular}

Four fixed factors (population, sex, treatment, litter order), three random factors (breeding pair identity, litter identity nested in treatment and in breeding pair identity) and one covariate (litter size) were included in the model. Post hoc comparisons are provided for significant variables (indicated in bold) only.

${ }^{1}$ Homogeneous (nonsignificant) subsets are given in parentheses; treatment codes: FRN (father removed and fed novel food); MRN (mother removed and fed novel food); MFN (both parents in home cage with novel food); FRS (father removed and fed standard food); and MRS (mother removed and fed standard food).

${ }^{2}$ Subsets are arranged from shortest to longest latencies; subscript $\mathrm{D}$ and $\mathrm{G}=$ desert and grassland respectively. 


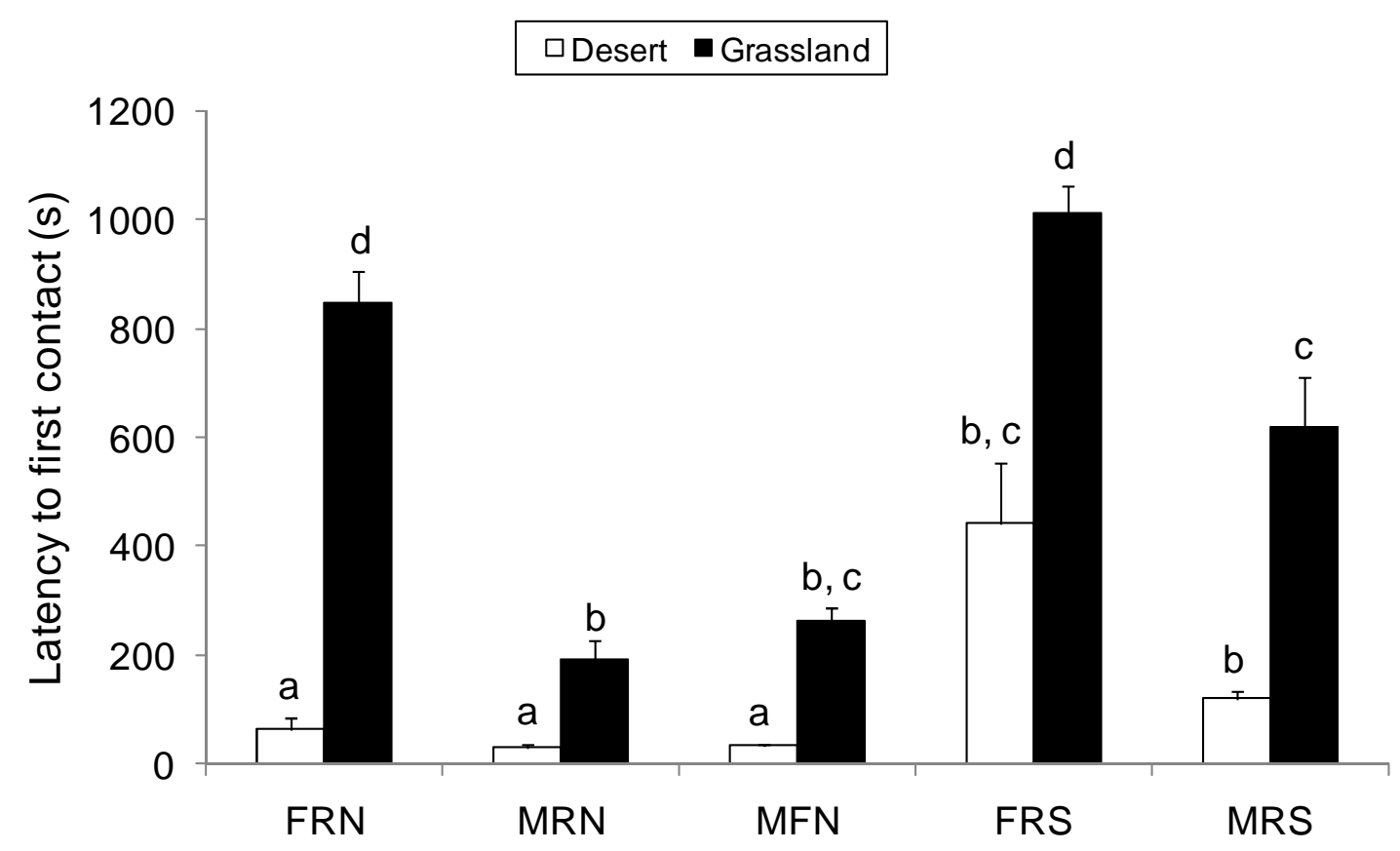

Figure 1. Mean + SE time taken for juvenile desert and grassland striped mice to make first contact with the novel food in five treatments: FRN (father removed and fed novel food); MRN (mother re moved and fed novel food); MFN (both parents in home cage with novel food); FRS (father removed and fed standard food); and MRS (mother removed and fed standard food). Bars with the same letters are not significantly different (population*treatment effect, post hoc comparisons). 


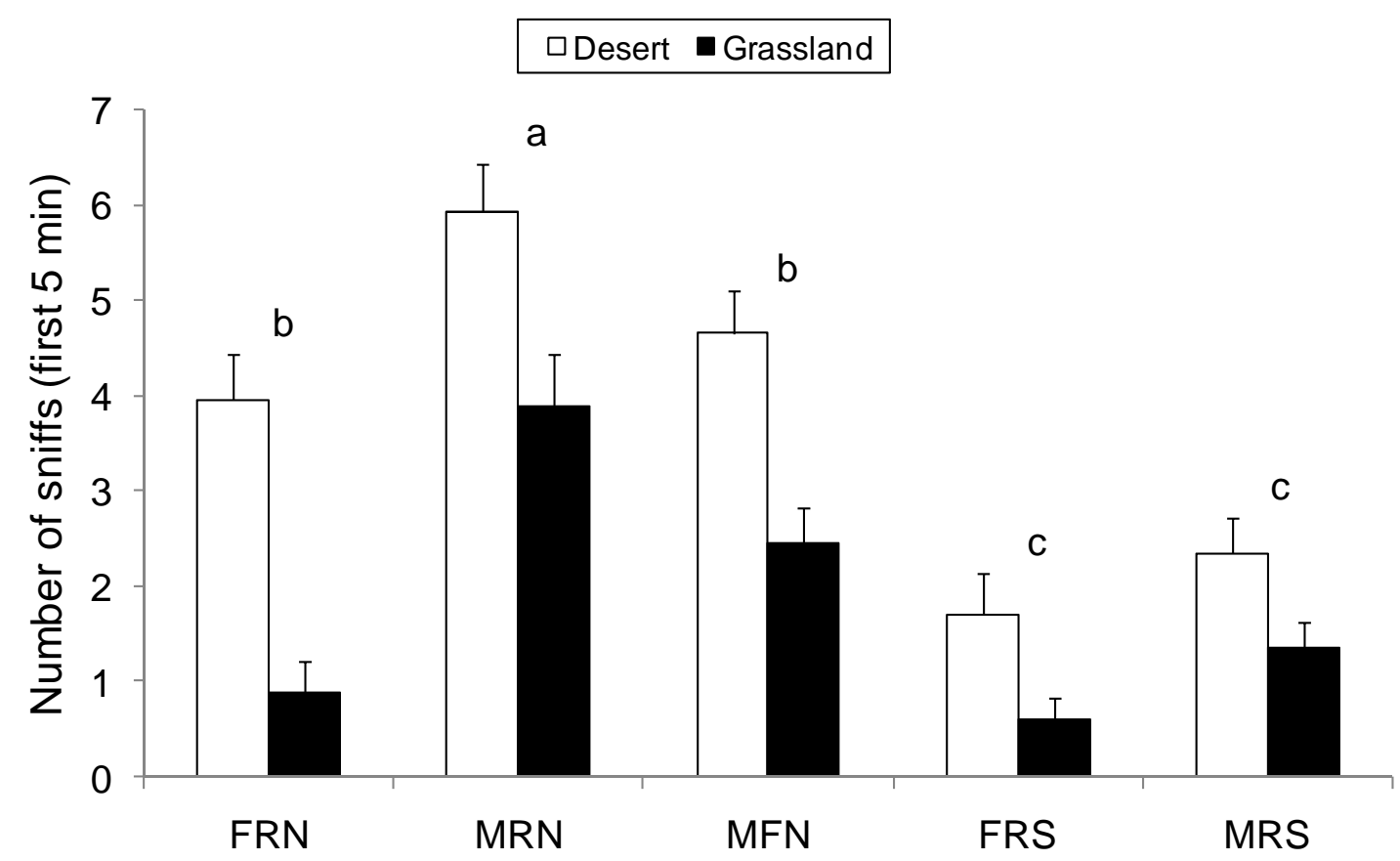

Figure 2. Mean + SE number of sniffs of novel food in the first 5 min after contact by juvenile desert and grassland striped mice in five treatments: FRN (father removed and fed novel food); MRN (mother removed and fed novel food); MFN (both parents in home cage with novel food); FRS (father removed and fed standard food); and MRS (mother removed and fed standard food). Bars with the same letters are not significantly different (treatment effect, post hoc comparisons). 


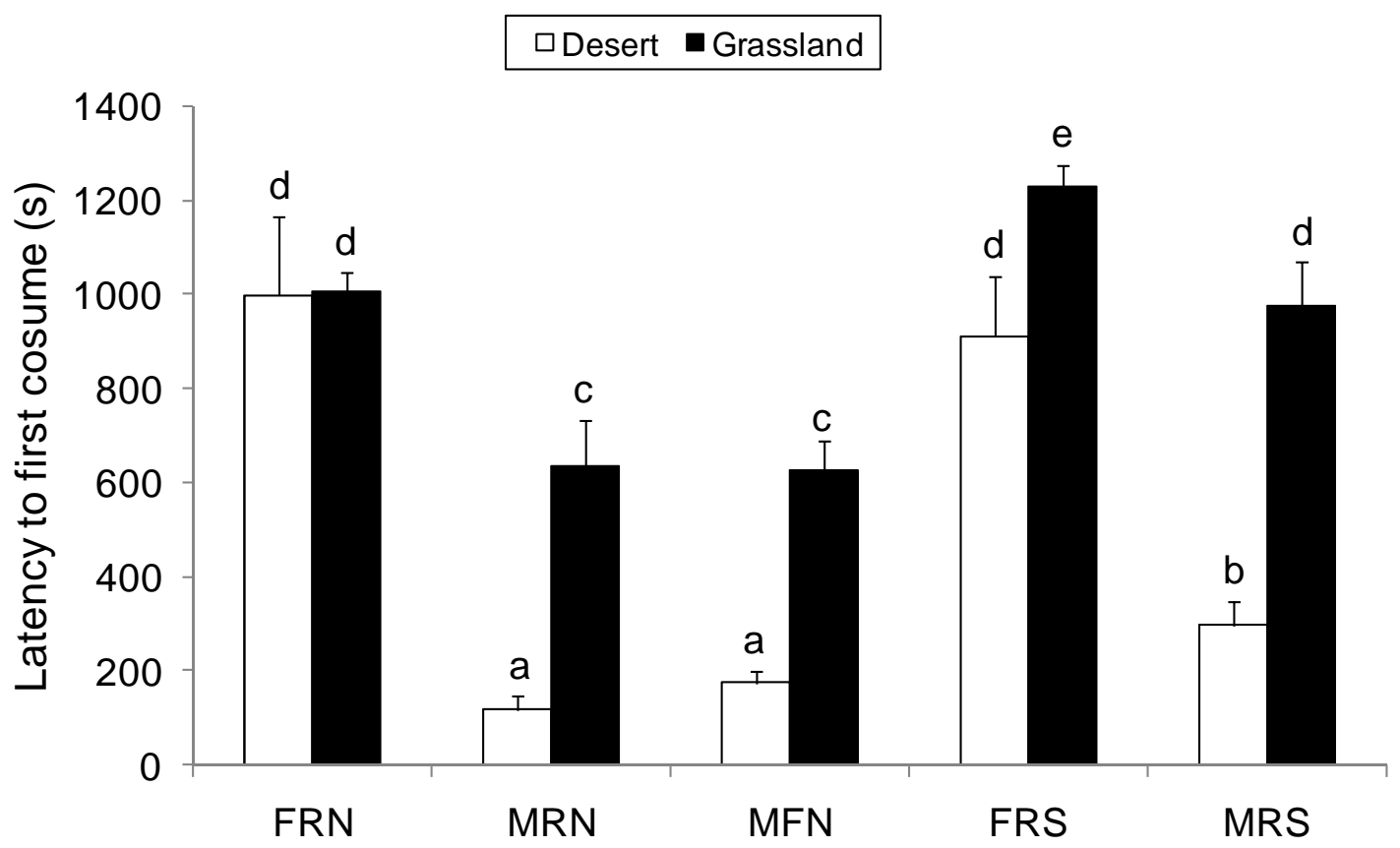

Figure. 3. Mean + SE time taken for juvenile desert and grassland striped mice to start consuming the novel food in five treatments: FRN (father removed and fed novel food); MRN (mother removed and fed novel food); MFN (both parents in home cage with novel food); FRS (father removed and fed standard food); and MRS (mother removed and fed standard food). Bars with the same letters are not significantly different (population*treatment effect, post hoc comparisons). 